\title{
Re: "Isolated rectal buttonhole tears in obstetrics: case series and review of the literature"
}

\author{
Joanna C. Roper ${ }^{1} \cdot$ Ranee Thakar $^{1} \cdot$ Abdul H. Sultan ${ }^{1}$ (I) \\ Received: 9 November 2020 / Accepted: 30 November 2020 / Published online: 6 January 2021 \\ (C) The International Urogynecological Association 2021
}

Dear Editor,

We would like to thank Habek and Luetić for their letter regarding our paper [1]. We whole-heartedly agree that the diagnosis and repair of rectal buttonhole tears is complex and, given their rarity, many clinicians lack experience of and expertise in this condition.

In the UK, undiagnosed rectal buttonhole tears are known to be a source of litigation, but most of these cases are settled out of court. It is also important that when such a tear is identified it is repaired by a senior, experienced obstetrician. We agree that the classification of obstetric anal sphincter injuries (OASIS) needs to be standardized and, since the introduction of the Sultan classification in 1999, it has now been incorporated in nearly all published national guidelines all over the world [2]. What our paper also adds is the recognition that a rectal buttonhole tear can occur in conjunction with a third- or fourth-degree tear, in the presence of an intact island of rectal mucosa. Indeed, the figure in your letter appears to also involve the anal sphincter. We appreciate the authors describing the two cases with poor outcomes that are undergoing litigation, as we have highlighted in our paper that such cases are not usually published.

We recognized the deficiencies in training regarding the classification, diagnosis and repair of OASIS over 20 years ago and began the first hands-on course in 2000 (www. perineum.net). We have subsequently demonstrated the benefits of running such hands-on workshops [3]. Over the last 7 years we have introduced the Prevention and Repair of Perineal Trauma Episiotomy Through Coordinated Training (PROTECT) international "train the trainers" course and there are a multitude of international trainers certified by the International Urogynecological Association (www.IUGA. org). We are currently evaluating training in the UK through an online survey of doctors (obstetric and colorectal surgeons) and midwives in OASIS and perineal trauma. We are also appraising the teaching methods and content of the available training courses throughout the UK. During the current COVID-19 pandemic many hands-on courses were cancelled and some are now exploring new ways of delivering the content, to ensure that training opportunities are not missed (www.perineum.net). We plan to make recommendations about the content and frequency of training, such as this, and to publish our data in the coming year.

Finally, we would like to congratulate Habek and Luetić in recognizing the need to include this topic in their postgraduate training, and would suggest that they consider standardizing their training as per the PROTECT programme (www.IUGA.org).

\section{References}

1. Roper JC, Thakar R, Sultan AH. Isolated rectal buttonhole tears in obstetrics: case series and review of the literature. Int Urogynecol J. 2020. https://doi.org/10.1007/s00192-020-04502-2.

2. Roper JC, Amber N, Wan OYK, et al. Review of available national guidelines for obstetric anal sphincter injury. Int Urogynecol J. 2020;31:2247-59. https://doi.org/10.1007/s00192-020-04464-5.

3. Andrews V, Thakar R, Sultan AH. Structured hands-on training in repair of obstetric anal sphincter injuries (OASIS): an audit of clinical practice. Int Urogynecol J. 2009;20:193-9. https://doi.org/10.1007/ s00192-008-0756-y.

Publisher's note Springer Nature remains neutral with regard to jurisdictional claims in published maps and institutional affiliations.

Abdul H. Sultan

abdulsultan@nhs.net

1 Croydon University Hospital, 530 London Road, Thornton Heath CR7 7YE, UK 